\title{
Evaluation of Platelet counts and its Indices in Various Clinical Conditions using Automated Hematology Analyzer in a Tertiary care Hospital
}

\author{
Niraimathi Manickam*, Renu G’boy Varghese and Anand Mohanraj \\ Department of Pathology, Pondicherry Institute of Medical Sciences, Puducherry, India
}

\begin{abstract}
Background and Aim: With wide use of Automated hematology analyzers, precise information on platelet indices viz. Mean Platelet Volume (MPV), Plateletcrit (PCT) and Platelet Distribution Width (PDW) are easily estimated. The aim was to correlate platelet indices in various clinical conditions.

Materials and Methods: It was a retrospective record based study for one month. Samples $(\mathrm{n}=501)$ were processed in ABX Pentra DF120 analyzer. To detect differences among various clinical conditions One-way ANNOVA test was used.

Results: Of 501 samples, 386 (77\%) showed normal counts, 57 (11.4\%) with thrombocytopenia and 58 (11.6\%) with thrombocytosis. Significant decrease in platelet count, PCT with increase in MPV, PDW was seen in cases of ITP and hepatic encephalopathy. Patients with bronchiectasis, fever and alcoholic liver disease showed increased MPV, PDW while tuberculosis and sepsis cases showed low levels with normal platelet counts.
\end{abstract}

Conclusion: Platelet indices varied significantly in different clinical conditions. It can be used as an additional marker of platelet activation and inflammation.

Keywords: : Platelet Count, Mean Platelet Volume, Plateletcrit, Platelet Distribution Width

\section{Introduction}

Widespread use of automated analyzers in hematology labs has made it possible to measure platelet indices like Mean platelet volume (MPV), Plateletcrit (PCT) and Platelet distribution width (PDW) more precisely. ${ }^{[1]}$ Though these indices are easily available, they are not reported because of lack of awareness among physicians and failure of standardization. ${ }^{[2]}$

The objective of this study was to correlate platelet count and its indices in various clinical conditions using $\mathrm{ABX}$ Pentra $\mathrm{DF}_{120}$ Hematology analyzer.

\section{Materials and Methods}

This retrospective record based study was conducted in the Department of Pathology, Pondicherry institute of medical sciences, Puducherry during the month of April 2015. All the blood samples processed for complete blood counts were included. Requisition forms without clinical details or additional samples from the same patients were excluded. Blood samples collected in EDTA vacutainer were processed within 2 hours in ABX Pentra DF ${ }_{120}$ analyzer. Quality control and calibration of the analyzer was according to the instructions of the manufacturer.
Healthy individuals who come for routine health check up with normal blood counts were included in the study for better comparison of platelet indices as there are no universal standardized normal values. To detect differences among various clinical conditions One-Way ANNOVA test was used. ${ }^{[1]}$ All statistical analysis was done using SPSS software. $p$ value of less than 0.05 was taken as significant.

\section{Results}

Among 501 cases, majority was between 40 and 60 years with male-female ratio of 1.9:1. Patients were categorized into 13 groups viz. Acute conditions (Fever, Sepsis, Inflammation e.g. appendicitis, pancreatic, hepatitis, etc.,), Chronic diseases (Diabetes, Hypertension, Tuberculosis), Antenatal cases, Diseases of Kidney, Liver, Lung, Cardiac, Neurology, Trauma cases, Snake bite, Hematological conditions, Dual diseases (any of the above two clinical conditions) and healthy individuals for Medical Check ups.

Many presented with acute conditions (29.8\%) followed by chronic diseases $(9.8 \%) .77 \%$ (386 cases) had normal platelet count with $57(11.4 \%)$ of thrombocytopenia and $58(11.6 \%)$ of thrombocytosis with majority being fever and inflammatory conditions. (Table 1) $83 \%$ of hepatic 
encephalopathy (HE), $50 \%$ of alcoholic liver disease (ALD) cases showed thrombocytopenia while, 57\% of valve disease, $33 \%$ of tuberculosis had thrombocytosis.

Table 2 shows mean values of platelet counts and its indices in various clinical conditions, which are statistically significant among various groups with $p<0.05$. Cases of ITP, HE showed significantly decreased Platelet count and
PCT with increased MPV and PDW.

Patients with Bronchiectasis, fever, ALD showed increased MPV and PDW with normal Platelet counts. Decreased MPV were noticed in cases of sepsis and tuberculosis. As the platelet counts move from thrombocytopenia to thrombocytosis, PCT increased while MPV and PDW decreased. (Table 3)

Table 1: Frequency wise distribution of various clinical conditions causing Thrombocytopenia and Thrombocytosis.

\begin{tabular}{|c|c|c|c|c|c|}
\hline THROMBOCYTOPENIA & NO. & $\%$ & THROMBOCYTOSIS & NO. & $\%$ \\
\hline $\begin{array}{l}\text { ACUTE: }(\mathbf{3 6 . 8 \% )} \\
\text { FEVER }\end{array}$ & 11 & 19.3 & $\begin{array}{l}\text { ACUTE: (32.8\%) } \\
\text { INFLAMMATORY }\end{array}$ & 14 & 24.1 \\
\hline INFLAMMATORY CONDITIONS & 8 & 14 & SEPSIS & 3 & 5.2 \\
\hline SEPSIS & 2 & 3.5 & FEVER & 2 & 3.5 \\
\hline $\begin{array}{l}\text { LIVER DISEASES: (14\%) } \\
\text { HEPATIC ENCEPHALOPATHY }\end{array}$ & 5 & 8.7 & $\begin{array}{l}\text { CHRONIC: }(20.7 \%) \\
\text { DIABETES }\end{array}$ & 8 & 13.8 \\
\hline ALCOHOLIC LIVER DISEASE & 3 & 5.3 & TUBERCULOSIS & 3 & 5.2 \\
\hline KIDNEY DISEASE & 7 & 12.3 & HYPERTENSION & 1 & 1 \\
\hline TRAUMA & 6 & 10.4 & $\begin{array}{l}\text { CARDIAC: }(15.5 \%) \\
\text { VALVULAR DISEASE }\end{array}$ & 4 & 6.8 \\
\hline $\begin{array}{l}\text { HEMATOLOGY (8.7\%) } \\
\text { ANEMIA }\end{array}$ & 3 & 5.3 & $\begin{array}{c}\text { CONGENITAL HEART } \\
\text { DISEASE }\end{array}$ & 3 & 5.2 \\
\hline ITP & 2 & 3.5 & CORONARY DISEASE & 2 & 3.5 \\
\hline DUAL DISEASES & 3 & 5.3 & TRAUMA & 7 & 11.9 \\
\hline COPD & 2 & 3.5 & STROKE & 3 & 5.2 \\
\hline CORONARY DISEASE & 1 & 1.8 & ANTENATAL CASE & 2 & 3.5 \\
\hline ANTENATAL CASE & 1 & 1.8 & TUMOR & 2 & 3.5 \\
\hline DIABETES & 1 & 1.8 & COPD & 2 & 3.5 \\
\hline TUBERCULOSIS & 1 & 1.8 & ANEMIA & 1 & 1.7 \\
\hline TUMOR & 1 & 1.8 & KIDNEY DISEASE & 1 & 1.7 \\
\hline TOTAL & 57 & 100 & TOTAL & 58 & 100 \\
\hline
\end{tabular}

Table 2: Platelet count and its indices in various clinical conditions.

\begin{tabular}{|c|c|c|c|c|c|}
\hline CLINICAL CONDITIONS & No. & Platelet $\left(\times 10^{\circ} / \mathrm{L}\right)^{*}$ & MPV (fI)* & PCT $(\%)^{*}$ & PDW $(\%)^{*}$ \\
\hline ACUTE: FEVER & 54 & $223 \pm 121$ & $8.8 \pm 1.0$ & $0.209 \pm 0.11$ & $16.2 \pm 4.1$ \\
\hline INFLAMMATION & 84 & $299 \pm 138$ & $8.5 \pm 0.9$ & $0.247 \pm 0.13$ & $14.6 \pm 2.9$ \\
\hline SEPSIS & 9 & $303 \pm 194$ & $8.5 \pm 1.1$ & $0.251 \pm 0.16$ & $15.3 \pm 4$ \\
\hline CHRONIC: DIABETES & 32 & $345 \pm 190$ & $8.7 \pm 0.9$ & $0.290 \pm 0.14$ & $14.8 \pm 2.5$ \\
\hline HYPERTENSION & 8 & $315 \pm 108$ & $8.4 \pm 0.7$ & $0.262 \pm 0.09$ & $14.2 \pm 1.8$ \\
\hline TUBERCULOSIS & 9 & $319 \pm 176$ & $8.1 \pm 0.8$ & $0.252 \pm 0.13$ & $14.4 \pm 2.9$ \\
\hline ANTENATAL CASES & 36 & $295 \pm 84$ & $8.6 \pm 0.8$ & $0.239 \pm 0.08$ & $14.8 \pm 2.5$ \\
\hline $\mathrm{C}^{\dagger} \mathrm{KIDNEY}$ DISEASE & 31 & $272 \pm 122$ & $8.7 \pm 1.0$ & $0.234 \pm 0.1$ & $15.7 \pm 2.8$ \\
\hline LIVER CASES: ALD ${ }^{\ddagger}$ & 6 & $174 \pm 107$ & $8.8 \pm 0.6$ & $0.151 \pm 0.09$ & $15.7 \pm 1.1$ \\
\hline $\mathrm{H}^{\S}$ ENCEPHALOPATHY & 6 & $115 \pm 70$ & $9.5 \pm 1.2$ & $0.109 \pm 0.05$ & $18.2 \pm 4.4$ \\
\hline LUNG: BRONCHIECTASIS & 5 & $313 \pm 26$ & $9.3 \pm 0.4$ & $0.289 \pm 0.02$ & $18.2 \pm 2.8$ \\
\hline COPD & 36 & $287 \pm 100$ & $8.4 \pm 0.8$ & $0.237 \pm 0.07$ & $14.5 \pm 2.5$ \\
\hline CARDIAC: CAD $\pi$ & 30 & $295 \pm 71$ & $8.6 \pm 0.4$ & $0.252 \pm 0.06$ & $15.0 \pm 2.7$ \\
\hline CONG** HEART DISEASE & 10 & $367 \pm 152$ & $8.6 \pm 1.3$ & $0.274 \pm 0.14$ & $14.7 \pm 4.4$ \\
\hline
\end{tabular}




\begin{tabular}{|l|c|c|c|c|c|}
\hline CLINICAL CONDITIONS & No. & Platelet $(\times 10 \% / L) *$ & MPV (fI)* & ${\text { PCT }(\%)^{*}}^{*}$ PDW (\%)* \\
\hline VALVE DISEASE & 7 & $\mathbf{4 0 2} \pm 109$ & $\mathbf{7 . 9} \pm 0.5$ & $\mathbf{0 . 2 7 7} \pm 0.15$ & $\mathbf{1 2 . 8} \pm 1.3$ \\
\hline NEURO: STROKE & 20 & $\mathbf{3 3 8} \pm 108$ & $\mathbf{8 . 4} \pm 0.8$ & $\mathbf{0 . 2 8 0} \pm 0.14$ & $\mathbf{1 4 . 3} \pm 2.3$ \\
\hline CER ${ }^{\dagger \dagger}$ VEIN THROMBOSIS & 4 & $\mathbf{3 0 9} \pm 71$ & $\mathbf{8 . 6} \pm 0.8$ & $\mathbf{0 . 1 8 5} \pm 0.14$ & $\mathbf{1 4 . 8} \pm 2.3$ \\
\hline TRAUMA CASES & 46 & $\mathbf{2 8 4} \pm 141$ & $\mathbf{8 . 5} \pm 0.8$ & $\mathbf{0 . 2 1 8} \pm 0.11$ & $\mathbf{1 5 . 1} \pm 2.6$ \\
\hline SNAKE BITE & 4 & $\mathbf{2 6 4} \pm 95$ & $\mathbf{8 . 3} \pm 0.3$ & $\mathbf{0 . 2 2 0} \pm 0.02$ & $\mathbf{1 4 . 4} \pm 0.6$ \\
\hline HEMATOLOGY: ITP & 4 & $\mathbf{1 4 9} \pm 103$ & $\mathbf{9 . 8} \pm 1.2$ & $\mathbf{0 . 1 3 0 \pm 0 . 0 9}$ & $\mathbf{2 0 . 3} \pm 5.4$ \\
\hline ANEMIA & 11 & $\mathbf{2 4 8} \pm 137$ & $\mathbf{8 . 4} \pm 0.6$ & $\mathbf{0 . 2 0 8} \pm 0.13$ & $\mathbf{1 5 . 2} \pm 1.9$ \\
\hline DUAL DISEASES & 9 & $\mathbf{1 9 5} \pm 83$ & $\mathbf{8 . 7} \pm 1.3$ & $\mathbf{0 . 1 7 1} \pm 0.07$ & $\mathbf{1 5 . 4} \pm 2.8$ \\
\hline MEDICAL CHECK UP & 38 & $\mathbf{2 7 4} \pm 67$ & $\mathbf{8 . 6} \pm 0.8$ & $\mathbf{0 . 2 3 3} \pm 0.05$ & $\mathbf{1 4 . 7} \pm 2$ \\
\hline TOTAL & $\mathbf{5 0 1}$ & & & \\
\hline
\end{tabular}

One-way ANNOVA test, $p<0.05\left({ }^{*}\right.$ Mean \pm Standard deviation, ${ }^{\dagger}$ Chronic, ${ }^{*}$ Alcoholic liver disease, ${ }^{\S}$ Hepatic, ${ }^{\circ}$ Coronary artery disease, ${ }^{* *}$ Congenital, ${ }^{\dagger C}$ Cerebral $)$

Table 3: Relationship among platelet counts and its indices.

\begin{tabular}{|c|c|c|c|c|c|c|}
\hline VARIABLE & No. & $\%$ & Platelet (×109/L) M $\pm \mathrm{SD}^{\dagger}$ & MPV (fl) M \pm SD $^{\dagger}$ & $\mathrm{PCT}(\%) \quad \mathrm{M} \pm \mathrm{SD}^{\dagger}$ & PDW (\%) M \pm SD $^{\dagger}$ \\
\hline Thrombocytopenia & 57 & 11.4 & $274 \pm 67$ & $8.6 \pm 0.8$ & $0.233 \pm 0.05$ & $14.7 \pm 2$ \\
\hline Normal platelet & 386 & 77 & $274 \pm 67$ & $8.6 \pm 0.8$ & $0.233 \pm 0.05$ & $14.7 \pm 2$ \\
\hline Thrombocytosis & 58 & 11.6 & $274 \pm 67$ & $8.6 \pm 0.8$ & $0.233 \pm 0.05$ & $14.7 \pm 2$ \\
\hline TOTAL & 501 & 100 & & & & \\
\hline
\end{tabular}

Mean \pm Standard deviation

\section{Discussion}

Platelets play a diverse role in hemostasis, inflammation, angiogenesis, regeneration, and repair. ${ }^{[3,4,5]}$ That is why; platelet count and its indices are being evaluated in many clinical conditions. MPV is the widely studied parameter in literature. It reflects platelet size, function and activity. ${ }^{[3,6]}$ Any conditions that enlarge the platelet size also raise the MPV. It is thought that young platelets, recently released from bone marrow are larger and becomes smaller as it ages. ${ }^{[7,8]}$ On the contrary, few think ${ }^{[9]}$ that the size of the platelets is not related to age, but to the ploidy class of the megakaryocytes. ${ }^{[10]} \mathrm{PCT}$ is the indicator of platelets in a unit volume of blood ${ }^{[1]}$ while PDW is considered to be the specific marker for platelet activation ${ }^{[12]}$, as it does not increase with platelet distension. ${ }^{[6]}$

In the present study, relationship among platelet counts and its indices were studied. As already proved in the literature ${ }^{[13,14]}$, Platelet count and PCT are linearly related while MPV \& PDW shows inverse relation with platelet count. This happens to maintain hemostasis by preserving constant platelet mass. ${ }^{[6]}$ Also analyzed were platelets and its indices in various clinical conditions by categorizing the patients into 13 groups.

Platelet indices in ITP and Liver diseases: Cases of ITP and HE in this study showed significant decrease in platelet count \& PCT with increase in MPV \& PDW. In thrombocytopenia, increased MPV is seen in case of destructive thrombocytopenia while decreased MPV is seen in hypo-proliferative thrombocytopenia. ${ }^{[15]}$ In ITP, immune mediated destruction of platelet occurs in peripheral blood resulting in low platelet count whereas raised MPV and PDW reflect increase in production rate. ${ }^{[1]}$

In patients with liver disease, low counts may be due to hypersplenism, suppression by virus, decreased thrombopoetin production or autoimmune destruction. ${ }^{[16]}$ According to Pérez et al ${ }^{[17]}$, thrombocytopenia is a predictor of encephalopathy in a patient with chronic liver disease. Many studies have reported raised MPV and PDW in many hepatic diseases such as steatosis, hepatitis, and cirrhosis as a result of platelet activation. ${ }^{[18]}$ Patients with ALD in this study also showed raised MPV and PDW.

Platelet indices in inflammatory diseases: Raised MPV as a result of platelet activation is associated with numerous inflammatory diseases. ${ }^{[19]}$ Release of young platelet from bone marrow by certain cytokines released during inflammatory diseases is the cause of raised MPV. ${ }^{[20]}$ Larger platelets reflect greater content of granules and imply greater efficiency in its hemostatic and pro-inflammatory function. [21] Accordingly, cases with fever and bronchiectasis showed raised MPV \& PDW in this study. It is a known fact that bronchiectasis is a parenchymal lung disease that develops as a result of chronic inflammation and recurrent pulmonary infections. Raised MPV may also be due to the invasiveness of the disease or its antibiotic resistance. But 
some studies show conflicting results of insignificant to low levels of MPV during exacerbations. ${ }^{[22]}$

Contradicting the above scenario, patients with tuberculosis in this study showed decreased MPV and cases of sepsis and inflammatory conditions showed lower values than expected. On review of literature, certain inflammatory conditions like rheumatoid arthritis, ankylosing spondylitis, ulcerative colitis and acute pancreatitis were documented with low MPV. ${ }^{[3,18]}$ This is because of the consumption and sequestration of large active platelets in the vascular segments ${ }^{[23]}$ or at the inflammation site. ${ }^{[20]}$ Low MPV may also be due to persistent activation of platelets by endotoxins and immunoglobulin leading to granular exhaustion, platelet shrinkage and decreased reservation. ${ }^{[24]}$ Low MPV in tuberculosis is explained by the pro-inflammatory cytokines like IL6 and acute phase reactants produced during active phase that impairs megakaryopoiesis thereby releasing small platelets. ${ }^{[25]}$ According to Baynes et al, ${ }^{[26]}$ low MPV is due to decreased lifespan of platelets in spite of increased thrombopoiesis.

This dual role of MPV in the inflammatory diseases can be explained by correlating the intensity of inflammation with raised MPV seen in low-grade inflammation while decreased MPV is seen in high-grade inflammatory condition. ${ }^{[3,5,21]}$

Platelet indices in cardiac and neurological diseases: Raised MPV is proved to be an independent risk factor for cardio and cerebrovascular diseases in many studies. ${ }^{[1,3]}$ But the present study did not show raised levels in patients with heart diseases or stroke, probably because of the treatment with no thrombotic risk.

The limitations of this study include small sample size, single platelet indices value and the lack of treatment history. MPV is a sensitive marker that varies widely based on blood sampling, storage, drugs and duration between collection and analysis. ${ }^{[22]}$ It is recently studied that trends in changes of platelet count and MPV is a more reliable marker of prognosis rather than single absolute values ${ }^{[27]}$ as it explains the progressive platelet activation following initial insult as a marker of increasing endothelial injury.

\section{Conclusion}

Platelet indices are simple, non-invasive, and highly reproducible, routine counts at no additional cost, which can aid in diagnosis and prognosis of many diseases. High MPV, PDW was found in ITP, liver diseases, and inflammatory conditions like bronchiectasis and fever while low MPV were documented in tuberculosis and sepsis cases. Hence these indices can be used as an additional marker of Platelet activation and inflammation. Further studies in large scale have to be undertaken to prove its role in various diseases along with the standardization of its normal values.

\section{References}

1. Shah AR, Chaudhari SN, Shah MH. Role of Platelet parameters in diagnosing various clinical conditions. Natl J Med Res. 2013;3:162- 5.

2. Botma J, Mogongoa LF, Jaftha AD, Janse van Rensburg W. Reference ranges for platelet indices using Sysmex XE-2100 blood analyser. Medical technology SA 2012;26(2):17-21.

3. Suvak B, Torun S, Yildiz H, Sayilir A, Yesil Y, Tas A et al. Mean platelet volume is a useful indicator of systemic inflammation in cirrhotic patients with ascitic fluid infection. Annals of Hepatology. 2013;12(2):294-300.

4. Cabar FR, Fettback PB, Pereira P, Zugaib M. Serum markers in the diagnosis of tubal pregnancy. Clinics. 2008;63:701-8.

5. Artunc UB, Pala HG, Calik E, Oruc KS. Can mean platelet volume and platelet distrubition width be possible markers or ectopic pregnancy and tubal rupture? (MPV and PDW in ectopic pregnancy). Pak J Med Sci. 2014;30(2):352-5.

6. Nergiz AS, Altınkaya S, Kü.ük M, Demircan SS, Yüksel $\mathrm{H}$. The association between platelet indices and recurrent pregnanacy loss.Gynecol Obstet Reprod Med. 2014;20:146-9.

7. Van der Lelie J, Von dem Borne AEG. Increased mean platelet volume in septicaemia. J Clin Pathol. 1983;36:693-6.

8. Karpatkin S. Heterogeneity of human platelets. I. Metabolic and kinetic evidence suggestive of young and old platelets. J Clin Invest. 1969;48:1073-82.

9. Paulus JM. Platelet size in man. Blood. 1975;46:321-36.

10. Karpatkin S, Garg SK, Siskind GW. Autoimmune thrombocytopenic purpura and the compensated thrombolytic state. Am J Med. 1971;51:1-4.

11. Bain BJ, Bates I. Basic haematological techniques. In: Lewis SM, Bain BJ, Bates I, editors. Dacie and Lewis practical haematology. 9th edn. Edinburgh: Churchill Livingstone 2001.

12. Öztürk ZA, Dag MS, Kuyumcu ME, Cam H, Yesil Y, Yilmaz $\mathrm{N}$ et al. Could platelet indices be new biomarkers for inflammatory bowel diseases? Eur Rev Med Pharmacol Sci. 2013;17:334-41.

13. Jackson SR, Carter JM. Platelet volume: laboratory measurement and clinical application. Blood Rev. 1993;7(2):104-13.

14. Chandrashekar V. Plateletcrit as screening tool for detection of platelet quantitative disorders. J Hematol. 2013;2(1):22-6.

15. Guclu E, Durmaz Y, Karabay O. Effect of severe sepsis on platelet count and their indices. Afr Health Sci. 2013;13(2): 333-8.

16. Peck-Radoslavljevic M. Hypersplenism. Eur J Gastroenterol Hepatol. 2001;13: 317-23.

17. Paniagua PA, Flores AG. Thrombocytopenia: risk factor for encephalopathy in a patient with liver failure. Med Int Mex. 2010;26(6):561-7. 18. Hu Y, Lou Y, Chen Y, Mao W. 
Evaluation of mean platelet volume in patients with hepatitis B virus infection. Int J Clin Exp Med. 2014;7(11):4207-13.

18. Koc S, Eyibilen A, Erdogan AS. Mean platelet volume as inflammatory marker in sinusitis. Eur $\mathrm{J}$ Gen Med. 2011;8(4):314-7.

19. Gasparyan AY, Ayvazyan L, Mikhailidis DP, Kitas GD. Mean Platelet Volume: A Link Between Thrombosis and Inflammation? Curr Pharm Des. 2011;17:47-58.

20. Thompson CB, Jakubowski JA, Quinn PG, Deykin D, Valeri CR. Platelet size as a determinant of platelet function. J Lab Clin Med. 1983;101:205-13.

21. Uysal P, Tuncel T, Erge DO, Hocaoglu AB, Karaman O, Uzuner N. Does Mean Platelet Volume in Children with Bronchiectasis Predict Exacerbations? International Journal of Hematology and Oncology. 2014;24:54-9.

22. Saxena D, Tandon M, Gedam B S. Role of Mean platelet volume in diagnosis of acute appendicitis. IJBR. 2015; 6(04):235-7.
23. Laffi G, Marra F, Gresele P, Romagnoli P, Palermo A, Bartolini $\mathrm{O}$ et al. Evidence for a storage pool defect in platelets from cirrhotic patients with defective aggregation. Gasteroenterology. 1992;103(2): 641-6.

24. Ogawa T, Uchida H, Kusumoto Y, Mori Y, Yamamura Y, Hamada S. Increase in tumor necrosis factor alpha-and interleukin-6-secreting cells in peripheral blood mononuclear cells from subjects infected with Mycobacterium tuberculosis. Infect Immun. 1991;59(9):3021-25.

25. Baynes RD, Bothwell TH, Flax H, McDonald TP, Atkinson $\mathrm{P}$, Chetty $\mathrm{N}$ et al. Reactive thrombocytosis in pulmonary tuberculosis. J Clin Pathol. 1987;40(6):676-9.

26. Zampieri FG, Ranzani OT, Sabatoski V, Possolo de souza $\mathrm{H}$, Barbeiro H, Cruz da Neto LM et al. An increase in mean platelet volume after admission is associated with higher mortality in critically ill patients. Ann of Intensive Care 2014;4:20-8. 